\title{
Technical-economical optimization of horizontal axis wind turbines by means of the genetic algorithm
}

\author{
Amir Jafary Moghaddam ${ }^{1}$, Abdollah Khalesi Doost ${ }^{2^{*}}$ \\ ${ }^{1}$ Department of Mechanical Engineering, Science and Research Branch, Islamic Azad University, Semnan, Iran \\ ${ }^{2}$ Mechanical Group, Engineering Faculty, Islamic Azad University, Semnan Branch, Semnan, Iran; \\ *Corresponding Author: ab.khalesi@yahoo.com
}

Received 1 September 2013; revised 1 October 2013; accepted 8 October 2013

Copyright (C) 2013 Amir Jafary Moghaddam, Abdollah Khalesi Doost. This is an open access article distributed under the Creative Commons Attribution License, which permits unrestricted use, distribution, and reproduction in any medium, provided the original work is properly cited. In accordance of the Creative Commons Attribution License all Copyrights (C) 2013 are reserved for SCIRP and the owner of the intellectual property Amir Jafary Moghaddam, Abdollah Khalesi Doost. All Copyright (C) 2013 are guarded by law and by SCIRP as a guardian.

\begin{abstract}
Wind turbine design is a trade-off between its potentially generated energy and manufacturing cost represented by the area of turbine surface in this research, and both factors are highly influenced by a number of design parameters. In this research, first, a weighted sum of these factors, with a negative weight for power, is assumed as the performance function to be minimized. Then, blade element modeling was performed for class NACA turbines to estimate the generated power based on the effective wind velocity in the area. As a novelty, a new algorithm based on fuzzy logic was proposed to determine the effective wind velocity by using the history of wind velocity in the area. The wind velocity, therefore, the generated power by a wind turbine, is largely dependent on its operation area. In the end, the genetic algorithm with decimal numeric genes was employed to determine the optimal design parameters of the turbine based on the recorded data. This study resulted in a computer program which integrated calculations of fluid dynamics into the genetic algorithm to optimally determine an appropriate turbine (its geometric parameters). The implementation of the proposed method on two different regions ended up with the design of the blade NACA5413 for Manjil and the blade NACA4314 for Semnan, both in Iran.
\end{abstract}

Keywords: Horizontal Wind Turbines; Genetic Algorithm; Element Modeling of the Blade; Fuzzy Sets; Optimization; Iran

\section{INTRODUCTION}

People of Iran and Afghanistan circa 200 BC learned how to bridle wind energy in its early technologic form, namely vertical axis windmills, and later around 1300 $\mathrm{AD}$, horizontal axis windmills appeared in Netherlands and the areas around Mediterranean Sea. Nowadays, due to problems such as environmental pollutions, restricted fossil resources and the ever-increasing demand for electric energy, people's attention has been paid to the wind energy again, and this is quite evident in the trend of most recent studies [1].

One of the important issues addressed in the study and design of systems of electricity generation from wind is how to optimize wind turbines employed for this purpose. Optimization calculations prior to these turbines' construction and utilization may reduce the construction/ manufacturing cost to a large extent and enhance generation capacity of the system. Most recently, a large number of studies have been conducted concerning optimization of wind turbines' parameters [ref.]. Mosetti et al. (1994) used the genetic algorithm to determine an optimal place for turbines so as to maximize total generation power but minimize total cost. Their method divided the intended set space into 100 square cells, and then the GA determined those cells where turbines should be mounted [2]. Fuglsang and Madsen (1999) suggested a numerical method to optimize wind turbines' rotors. They also, to minimize energy generation cost, proposed a better design for rotors of equal surface area [3]. In 2002, Benini and Toffolo used a multi-purpose optimization algorithm and aerodynamic calculations of the blade elements for horizontal axis wind turbines. They considered two objectives of annual energy generation and energy generation cost for optimization [4]. Models of 
wind turbines are essential for optimization, as experimental assessment of various designs is infeasible. In terms of modeling, Jureczko et al. (2005) suggested numerical methods based on finite elements' calculations [5]. Models based on Navier-Stokes equations have attracted much attention recently, for example by Minervino et al. (2011), to improve aircraft aerodynamics [6]. Articles by Kusiak et al. (2010) were examples of using optimization algorithms to design wind turbines [7,8]. Maki et al. (2012) proposed a multi-stage method for the optimization of wind turbines [9]. The genetic algorithm (GA) was suggested to be used to optimize various aspects of wind-based generation systems [ref.]. Different combinations of models and optimization algorithms were reported in the literature as shown by Table 1.

Wind energy and its utilization in Iran, in a similar vein, are receiving more attention in recent years [10]. Until recently, some studies have been carried out into the wind potentials of Iranian regions like Tehran [11], Yazd [12] and Shahr-e-Babak [13].

The present study introduces and then implements a method based on blade element modeling of turbines, together with the GA optimization with real number genes, and a fuzzy logic-based method to adjust wind velocity, and estimates the effective wind velocity. The proposed method is used to design optimal NACA turbines for Semnan and Manjil regions in Iran.

\section{STATEMENT OF THE PROBLEM AND THE PROPOSED METHOD}

This study is aimed to develop a method optimally determine type and geometric parameters of wind turbines for different regions based on their local wind information. Figure 1 illustrates the statement of the problem and the method proposed by this study. The total objective of the design is to satisfy both the following partially contradictory objectives 1) to maximize the generation capacity and 2) to minimize turbine construction cost. Therefore the objective function of the optimization problem is defined as

$$
f=w_{1} P_{m}+w_{2} \operatorname{Cost}
$$

where $P_{m}$ is the generated power, $w_{1}$ and $w_{2}$ are positive and negative weights. As a constraint, the allowed values of parameters such as turbine radius are limited.

The input to the problem is wind information of the region; an effective wind velocity is calculated based on this information through a fuzzy-inspired method detailed in Section 4. For any given set of turbine parameters, the area of turbine blade (as a representative of the

Table 1. Different combinations of models and optimization algorithms reported in the literature are presented.

\begin{tabular}{|c|c|c|c|c|c|c|}
\hline Objective & Variable & Algorithm & Model & Year & Author & Ref \\
\hline Cost + Power & $\begin{array}{l}\text { Location turbines in } \\
\text { the wind farm area }\end{array}$ & GA & $\begin{array}{l}\text { Riso Method to model } \\
\text { wind farm }\end{array}$ & 1994 & $\begin{array}{l}\text { Mosetti C.P. and } \\
\text { Diviacco B. }\end{array}$ & {$[2]$} \\
\hline $\begin{array}{c}\text { Cost }+ \\
\text { Annual energy }\end{array}$ & $\begin{array}{l}\text { Shape of rotor }+ \text { Airfoil } \\
\text { characteristics }+ \text { Rotor } \\
\text { configuration }\end{array}$ & $\begin{array}{l}\text { sequential linear programming } \\
+ \text { method of feasible directions }\end{array}$ & $\begin{array}{c}\text { blade element theory }{ }^{+} \\
\text {linear elastic I-beam model }\end{array}$ & 1999 & Fuglsang P., Madsen H.A. & {$[3]$} \\
\hline $\begin{array}{l}\text { The annual energy } \\
\text { production }+ \text { Cost }\end{array}$ & Rotor geometry & $\begin{array}{c}\text { Evolutionary multi-objective } \\
\text { optimization }\end{array}$ & blade element theory & 2002 & $\begin{array}{l}\text { Benini E., } \\
\text { Toffolo A. }\end{array}$ & {$[4]$} \\
\hline Blade mass & $\begin{array}{l}\text { Layer thickness } \\
\text { of the rotor }\end{array}$ & GA & $\begin{array}{l}\text { blade element theory }+ \\
\text { Finite Element }\end{array}$ & 2005 & $\begin{array}{c}\text { M. Jureczko, M. Pawlak, } \\
\text { and A. Me'zyk }\end{array}$ & {$[5]$} \\
\hline Power + Vibration & Turbine Options & Data mining methods & Experimental data & 2010 & $\begin{array}{l}\text { Kusiak A., Zheng H., } \\
\text { Song Z. }\end{array}$ & {$[7]$} \\
\hline $\begin{array}{l}\text { Annual energy }+ \\
\text { Mechanical quality } \\
\text { turbine }+ \text { Cost }\end{array}$ & $\begin{array}{c}\text { Rotor geometry } \\
\text { (Thickness, Height, } \cdots \text { ) }\end{array}$ & Optimizing multi-stage & Several simulation & 2012 & $\begin{array}{c}\text { Kevin Maki, Ricardo } \\
\text { Sbragio, Nickolas } \\
\text { Vlahopoulos }\end{array}$ & {$[9]$} \\
\hline
\end{tabular}

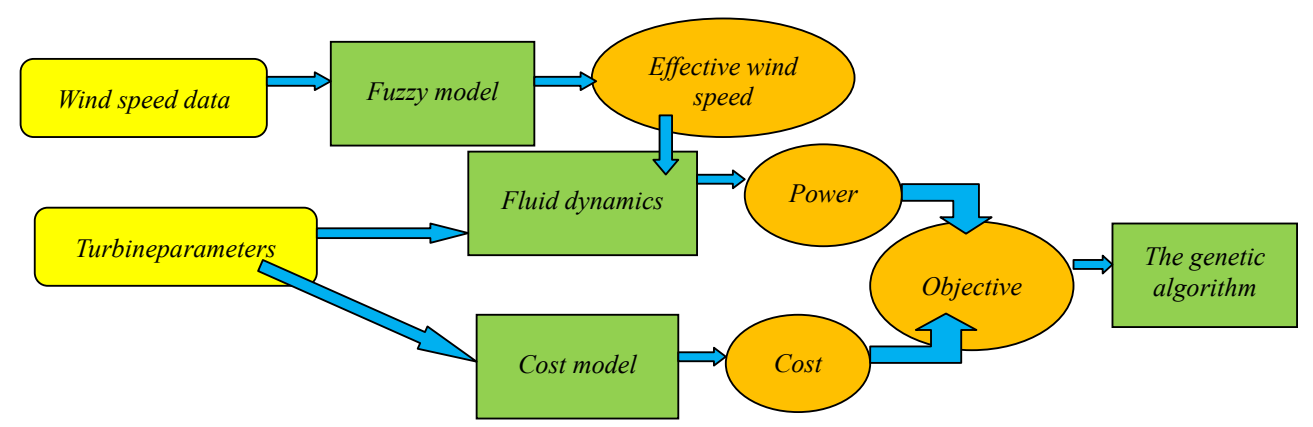

Figure 1. The schematic diagram of the method proposed to optimize wind turbines. 
manufacturing/construction cost) is calculated and a mathematical model of the turbine, detailed in Section 3, is made. The derived mathematical model produces the generated power by the turbine using the effective wind velocity value.

Due to nonlinearity of governing equations, and to avoid local optima, the genetic algorithm with real chromosomes, detailed in Section 5, was employed to find out the optimal parameters of this problem.

\section{MODELING OF THE BLADE AND OBJECTIVE CALCULATIONS}

Several theoretical modeling methods were suggested to analyze turbine blade performance in a state of flux. The most common method for this purpose, however, is the blade element modeling (BEM) [14]. This study employs the element modeling of wind turbine blades to extract their efficiency curves. To this end, axial force and moment are calculated. The axial force will amount to the momentum rate of change along the $\mathrm{x}$ axis, and the axial moment to the rate of change of angular momentum. Accordingly, the coefficient of power $\left(C_{p}\right)$ will have the below relation with the tip speed ratio (2) [14]:

$$
C_{p}=\frac{Q \omega}{\frac{1}{2} \rho \pi R^{2} v_{0}^{3}}=\lambda^{2} \int_{0}^{1} 8 b(1-a) \mu^{3} d \mu
$$

where $\rho$ represents the air density and $Q$ the moment, and $\omega$ and $R$ stand for the angular speed and the turbine radius, respectively. $v_{0}$ shows the wind velocity, $a$ and $b$ are the parameters defined for the resultant speed in relation to the blade in Equation (3):

$$
\begin{gathered}
v_{\text {res }}=\sqrt{v_{0}^{2}(1-a)^{2}+\omega^{2} r^{2}(1+b)^{2}} \\
v_{\text {res }}=\frac{v_{0}(1-a)}{\sin \beta}=\frac{\omega r(1+b)}{\cos \beta}
\end{gathered}
$$

$C_{p}-\lambda$ curve has a maximum value at which the generation power to turbine surface area will be the greatest. It should be noted that $\lambda$ is also related to " $a$ " and " $b$ " and, therefore, the Equation (2) does not merely serve as a simple function of degree 2 in terms of $\lambda$.

So the mechanical generation power of a wind turbine can be calculated from $P_{m}=C_{p}(\lambda, \beta) \frac{\rho A}{2} v_{\text {wind }}^{3}$, where $C_{p}(\lambda, \beta)$ represents efficiency coefficient of the wind turbine, and $\rho$ the air density $\left(\mathrm{kg} / \mathrm{m}^{3}\right)$. A stands for the blade swept area $\left(\mathrm{m}^{2}\right)$ and $v_{\text {wind }}$ for the wind velocity $(\mathrm{m} / \mathrm{s})$ and finally $\lambda$ and $\beta$ denote respectively the tip speed ratio and pitch angle (expressed in degrees).

For a given $\beta$ and a specific $\lambda$, we will achieve the greatest power coefficient $(\mathrm{Cp})$ which maximizes the generation power. In order to calculate this coefficient for different airfoils (all are given a NACA code), XFOIL program is employed [15].

Here, wind turbine cost model is regarded as a multinominal function of surface area, the coefficients of which are determined according to different economical conditions. The cost of turbine blade materials enters the multi-nominal in the form of a total coefficient. So cost model is shown Equation (4):

$$
\text { Cost }=C_{p a}\left\{200\left[\left(\frac{A}{200}\right)+0.1\left(\frac{A}{200}\right)^{2}+0.1\left(\frac{A}{200}\right)^{3}\right]\right\}
$$

where $A$ stands for the surface area of the circle swept by the turbine, and $C_{p a}$ denotes the coefficient of materials price. The objective function of the optimization problem appears to be a linear combination of generation power and construction costs (Equation (4)):

Where $W_{1}=-1$ and $W_{2}=1$, and the function of fitness should be minimized. However, weight values of this linear combination rely on the taste and objectives of the designer. If $W_{2}$ is considered dimension free, then for " $f$ " to be a function of the same type as that of cost the dimension of $W_{1}$ will be the same type as that of power unit price.

\section{WIND VELOCITY ADJUSTMENT METHOD}

Speed of a given region's wind serves as a random variable so a proper method is required to feed the wind velocity value to the turbine generation power calculations. Several approaches can be taken for this purpose. From among various methods to solve the problem some are, say, using the average wind speed over a number of years, using a value of the greatest probability (an expected value), carrying out various calculations by means of a random number generation (RNG) and using an average of the results obtained, and employing the fuzzy logic.

The average wind velocity is affected by both the general trend and the occurrence of specific events. On the other hand, this average on its own indicates inadequately data manner of changes. For example, these two sets of numbers $\{1,5,10,14,20\}$ and $\{10,10,10,10,10\}$ have the same average 10, although their uncertainty appears to be different. This is also true when we use a state of the greatest probability, that is, data uncertainty is not taken into account. Carrying out a large number of various calculations for optimization (in particular the genetic algorithm) seems to be very time consuming. So this study attempts to employ a method, on the basis of fuzzy set theory, which not only takes into consideration the uncertainty surrounding the most probable state but is also less time consuming. Fuzzy sets and the related mathematics took shape and developed by the second half 
of the twentieth century [16]. Today, fuzzy logic and systems have become one of the most widely used subjects in mathematics, engineering and human sciences [17].

In the problem of turbine optimization, we assume the wind velocity as a triangular fuzzy variable, the average velocity, the most probable velocity and the maximum wind velocity simultaneously determine its vertexes. The most probable state has the degree of membership 1, while other values appear to have less degrees of membership. Since the genetic algorithm requires to determine the extent of fitness and to compare the possible solutions to the problem, an appropriate method should be adopted to compare and rank fitness values obtained in the form of fuzzy numbers.

A method adopted here for ranking fuzzy numbers is based on the calculation of Alpha-cut integral for each fuzzy number [18]. The integral is defined as follows (Equation (5)):

$$
\operatorname{Val}(F)=\frac{\int_{0}^{1} \operatorname{Average}\left(F_{\alpha}\right) \cdot f(\alpha) \cdot d \alpha}{\int_{0}^{1} f(\alpha) \cdot d \alpha}
$$

where $F_{\alpha}$ can be obtained from the below Equation (6):

$$
F_{\alpha}=\{x \mid F(x) \geq \alpha\}
$$

$f(\alpha)$ is a weight function which is here assumed to equal the constant 1 . Using the above equations, we it can be presented that for a given trapezoidal fuzzy number with its four parameters $a, b, c$ and $d$, the Equation (7) will calculate the integral value:

$$
\operatorname{Val}(T(a, b, c, d))=\left(\frac{b+c}{2} \cdot w\right)+\left(\frac{a+d}{2} \cdot(1-w)\right)
$$

where

$$
w=\frac{\int_{0}^{1} \alpha \cdot f(\alpha) \cdot d \alpha}{\int_{0}^{1} f(\alpha) \cdot d \alpha}
$$

A triangular fuzzy numbers are a specific form of trapezoidal fuzzy numbers where $b=c$. Setting $f(\alpha)$ to the constant 1 , we will have $w=0.5$.

Therefore, any value obtained from the fitness function is mapped by means of its alpha-cut integral onto a number, and ranking and optimization are then performed [18].

\section{EVOLUTIONARY OPTIMIZATION ALGORITHM}

A group of complicated optimization problems are composed of a large number of parameters, nonlinear and non-analytical relations and multi-stage calculations, algebraic-based analytical methods may be considered inapplicable to solve these problems accurately enough.
Our problem of turbine optimization is such a problem. These problems can be solved by the methods developed based on a search in the space of all possible solutions. One of the possible approaches to solution search is to employ evolutionary algorithms. These algorithms are directed toward optimal solution(s) by constantly completing a set of preliminary solutions (preliminary population) over successive repetitions (generations). The genetic algorithm which is utilized by this study is the most applied, well-known member of evolutionary algorithms. This section presents a brief summary of the genetic algorithm $[19,20]$.

Components of a common genetic algorithm are as follows:

1) Objective function: The objective function represents the relation between a given problem's inputs (the optimal values of which are to be determined) and outputs (which in the form of a real number indicate the corresponding inputs' fitness). This function can appear either as an analytic relation between inputs and outputs or determines an output through, possibly complicated, algorithmic calculations.

2) Definition of chromosome: Solutions to a given problem require to be appropriately defined as a onedimensional string called chromosome so that they can be useable by the genetic algorithm and its processes. A chromose is formed by a number of smaller units called genes; each gene represents a parameter. The preliminary form of genetic algorithm defines chromosome as a binary string on which a possible solution to the problem is provided as a specific 1-0 configuration. Another more recent method, used in this research, is to assign real numbers in a specified range to each parameter (gene) and forming chromosomes as a string of these real numbers.

3) Preliminary population: Usually a number of chromosomes come randomly together to form a preliminary population. Descendent generations of chromosomes are then developed from the transformations of this preliminary population. In some cases, the preliminary population developed non-randomly or manual insertion of some chromosomes in the preliminary population may prove useful to solve the problem. In this research, the preliminary population is formed by chromosomes in which their genes are produced as following:

$$
p(i)=p_{\text {min }}+\left(p_{\max }-p_{\text {min }}\right) \times \text { rand },
$$

where $p(i)$ is the $i^{\text {th }}$ parameter (gene) in a chromosome with the range of $\left[p_{\min }, p_{\max }\right]$ and rand is a random number in the range of $[0,1]$.

4) Crossover: This operator simply operates as a simulator of reproduction operation in nature. In this operation, two parent chromosomes are selected, and the offspring chromosomes are created by the crossover of a 
part of one parent chromosome's genes and a complementary part from the other parent. The most common way for this process, namely, one point crossover, is shown in Figure 2, a part of one parent chromosome is combined prior to a certain point with a complementary part, after that point, of the other parent chromosome. The crossover process can also be defined in other forms such as multipoint crossover, crossover of more than two parents, and one random crossover point, among others. In this research, one-point cross over was employed and the cross over point was selected randomly.

5) Mutation: During this process, some chromosomes are randomly selected, and some of their genes go through a change in value. In binary chromosomes, zero simply changes into one and vice versa. In real chromosomes (and this research), in some of chromosomes, a gene is randomly selected and replaced by another random number in its designated range. In this research, $30 \%$ of chromoses go through mutation.

6) Elitist selection: This process takes place when some of the best solutions are directly transferred unchanged from a generation to the next generation. In this research, $20 \%$ of top chromosomes of each generation are directly transferred to the next generation.

7) Parent selection: Crossover process requires parents to be selected. Selection of a given chromosome as a parent chromosome has a probability proportionate to the corresponding fitness of that chromosome. There are various methods for parent selection; however, Roulette Wheel Selection serves as one of the most common methods and was employed in this research [19].

8) Termination criterion: A criterion is required to terminate the algorithm. For example, achieving a certain repetition number or consistency in the solution over several successive repetitions can operate as the termination criterion. Figure 3 illustrates the genetic algorithm flowchart. In this research, maximum of 165 has been considered for repetition number.

\section{SIMULATION RESULTS}

This section is allocated to the implementation of the method previously described so as to find optimal turbine parameters based on the wind velocity date obtained from Semnan and Manjil, Iran. The data used can be retrieved from http://www.iranhydrology.com/ or Iran Meteorological Organization [21].

The average monthly wind velocity in knots of Manjil for the years 1994 through 2010 is presented by Figure 4.

Using the data from Figure 4, a histogram representing the frequency of the above average values is developed as shown by Figure 5. Using this histogram, a wind velocity of the greatest probability and also possible

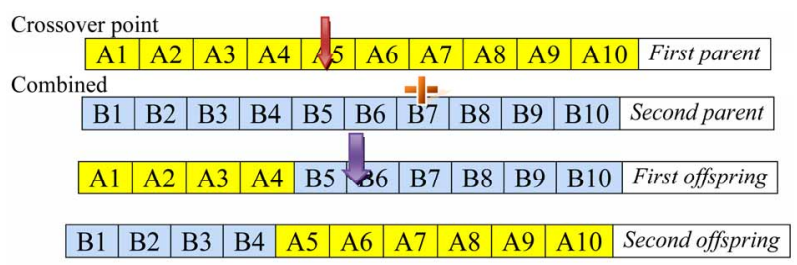

Figure 2. A one-point crossover process.

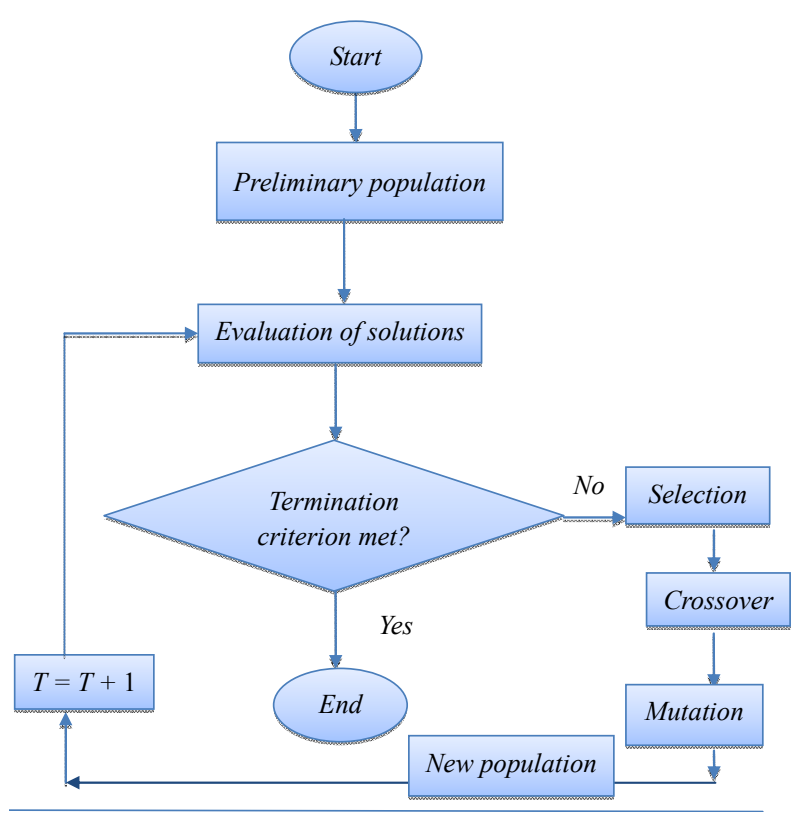

Figure 3. The genetic algorithm flowchart.

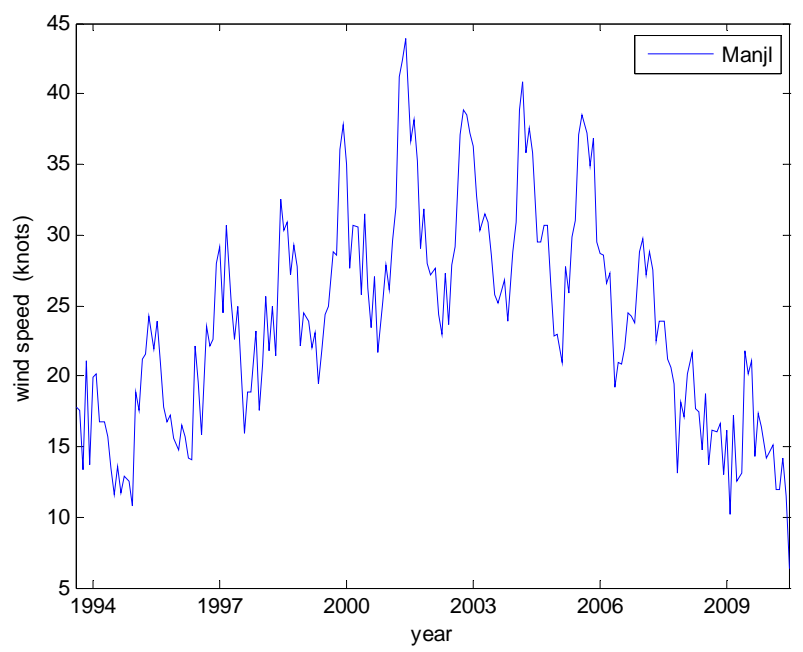

Figure 4. The average monthly wind speed in knots of Manjil for the years 1994 through 2010.

maximum and minimum values of the data under study can be determined.

As can be seen, the most probable wind velocity is roughly 24 knots, and the maximum and minimum wind velocitys amount to 45 and 6 knots, respectively. Therefore, wind velocity of Manjil region can be modeled with 
a triangular fuzzy variable of the parameters $(45,24,6)$ (Figure 6).

Wind velocity (in knots) data from Semnan for the years 1994 through 2010 are illustrated by Figures 7-9.

Using the alpha-cut method for the triangular fuzzy function of Figure 6, the value 24.75 was obtained. So this simulation assumes the effective wind velocity of Manjil to be 24.75 knots (equal to $12.72 \mathrm{~m} / \mathrm{s}$ ). However, we obtained the value 12.25 for the triangular fuzzy function of Figure 9, and accordingly the effective wind velocity of Semnan is set to 12.25 knots $(6.29 \mathrm{~m} / \mathrm{s})$.

To employ the genetic algorithm for our problem, we need first to define chromosomes properly. That is, optimization parameters which define chromosomes operate as a 7-element vector:

- First element: turbine radius $(r)$

- Second element: pitch angle $(\beta)$

- Third element: tip speed ration $(\lambda)$

- Fourth to seventh elements: airfoil codes of NACA- $x_{1}$ $x_{2} x_{3} x_{4}$

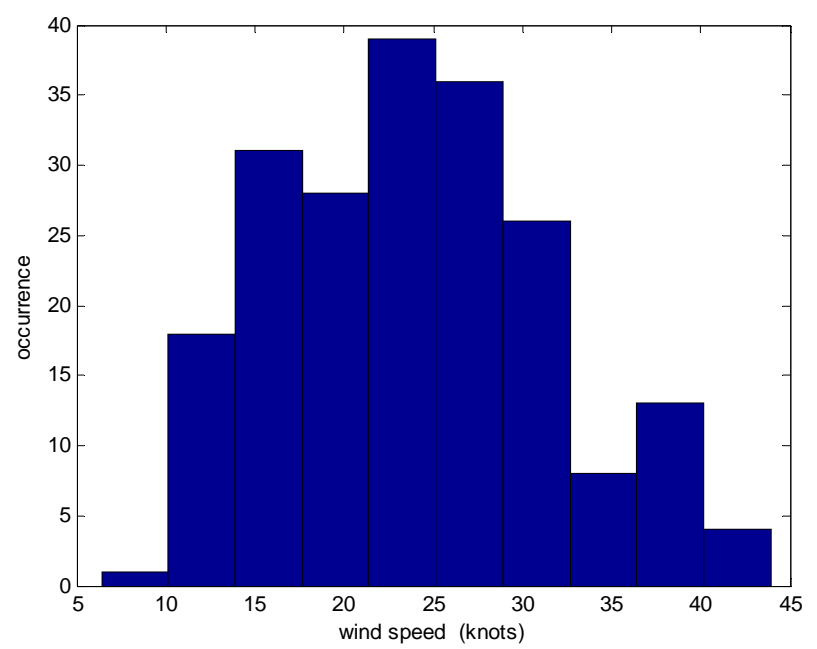

Figure 5. Histogram of wind speed data from Manjil.

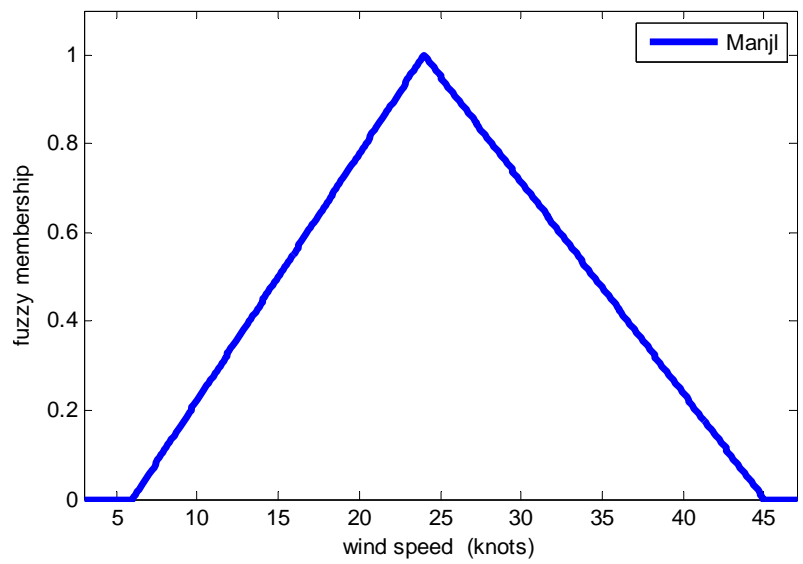

Figure 6. Fuzzy membership function of Manjil wind speed data.

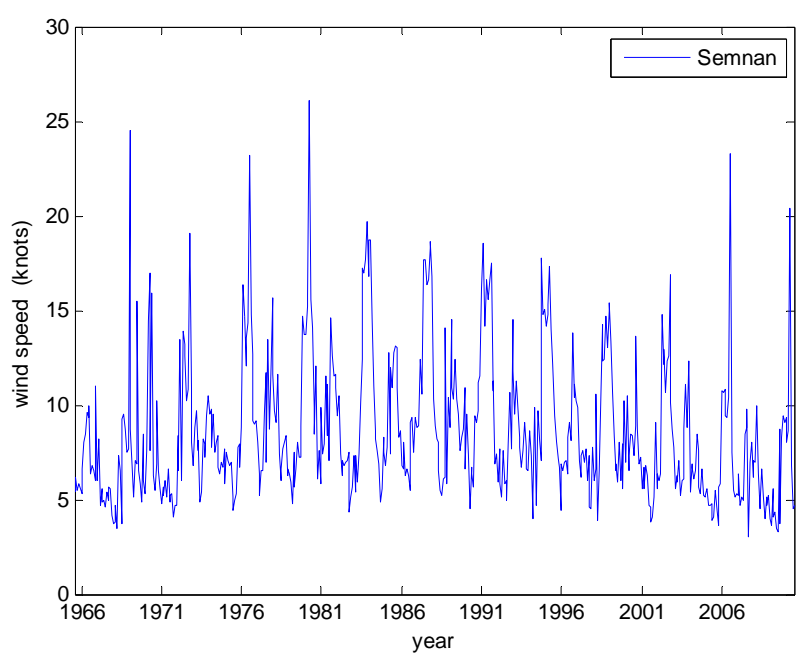

Figure 7. The average monthly wind speed in knots of Semnan for the years 1994 through 2010.

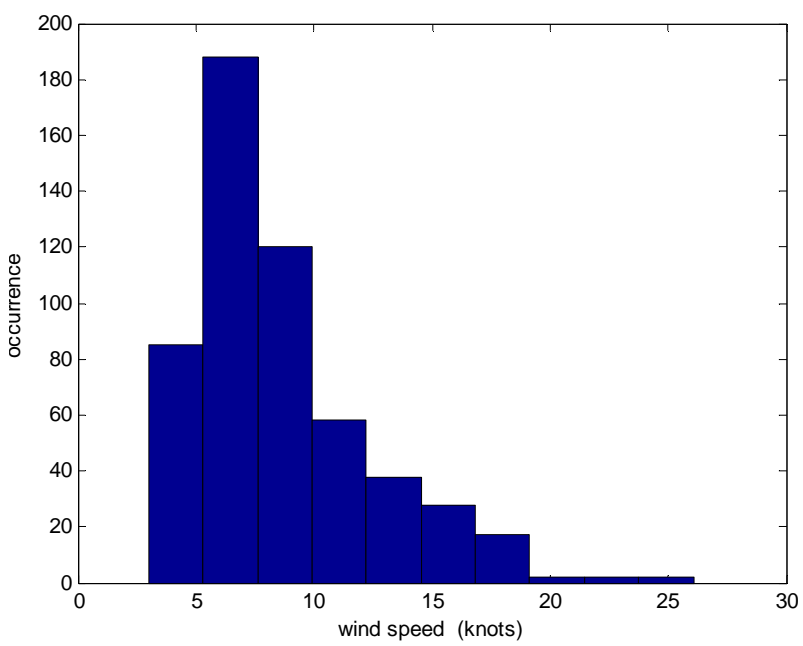

Figure 8. Histogram of wind speed data from Semnan.

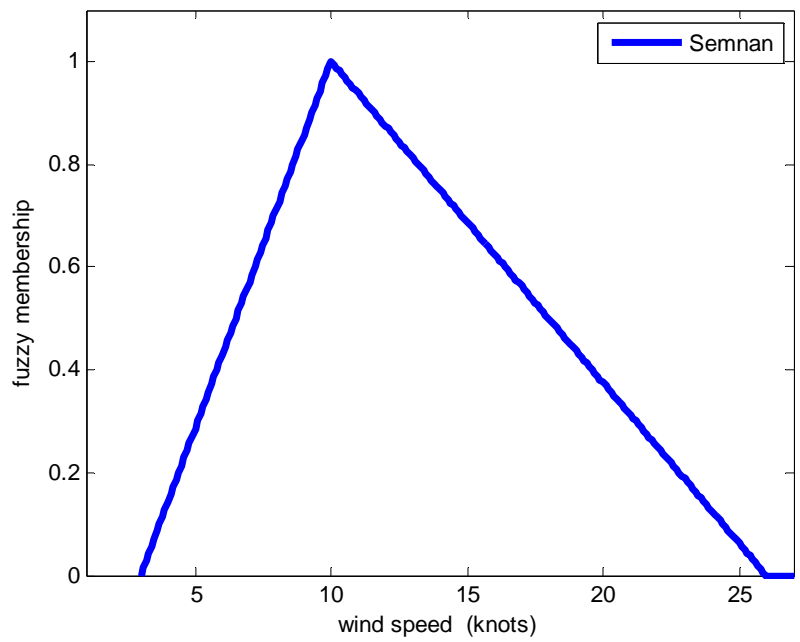

Figure 9. Fuzzy membership function of Semnan wind speed data. 
So any chromosome will be in the form of $\left[r, \beta, \lambda, x_{1}\right.$, $\left.x_{2}, x_{3}, x_{4}\right]$.

At any stage of fitness measurement, CFD calculations for the corresponding airfoil are conducted by XFOIL program using airfoil code (the last four digits of the chromosome). The result obtained is then used to calculate BEM. Next, $\mathrm{Cp}$ and then generation power are obtained, and the latter is fed to the function of fitness.

The trend of the objective function of the genetic algorithm for Manjil and Semnan, are shown by Figures 10 and $\mathbf{1 1}$ data as respectively.

The results of turbine features optimization of Manjil and Semnan as shown by Table 2 .

Figure 12 illustrates the airfoils NACA5413 and NACA4314.

In this research or similar research works, there are a number of sources of error that have been taken into account in this research:

1) Inaccuracies in mathematical models of the system (i.e. wind turbines) may result in wrong results.

2) Assigning non-realistic weights to the components of the objective function.

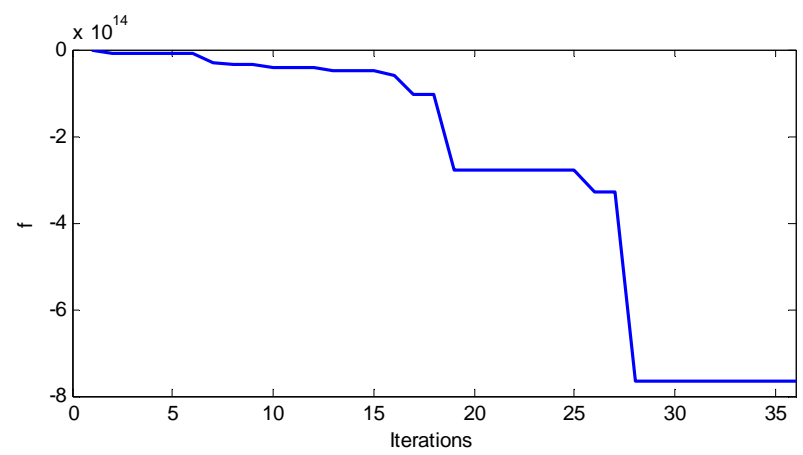

Figure 10. The convergence curve for the optimization of wind turbine airfoils (Manjil).

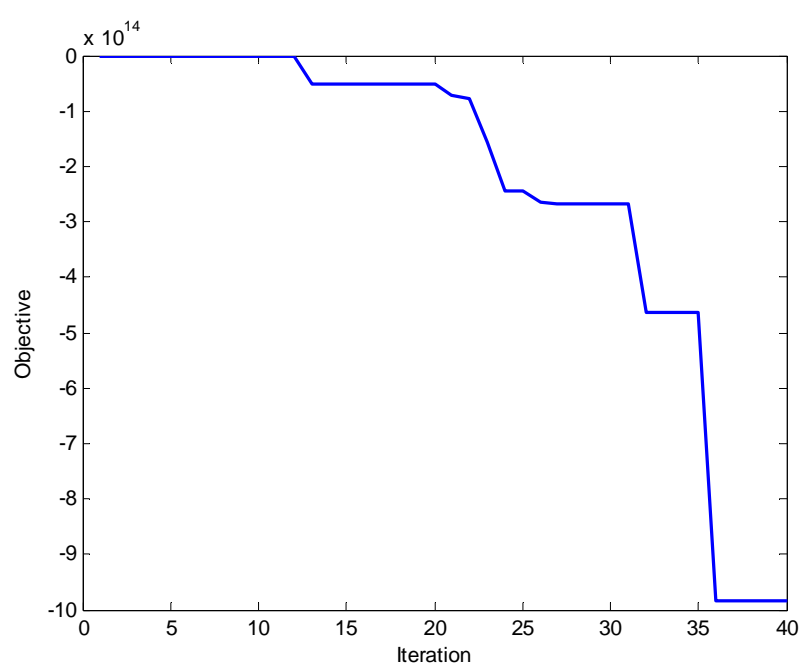

Figure 11. The convergence curve for the optimization of wind turbine airfoils (Semnan).
Table 2. The results of wind turbine airfoils optimization for Majil and Semnan data.

\begin{tabular}{|c|c|c|}
\hline \multirow{5}{*}{$\begin{array}{l}\text { Results of } \\
\text { airfoils } \\
\text { optimization } \\
\text { for Manjil } \\
\text { data }\end{array}$} & Feature & The value determined \\
\hline & Airfoil type & NACA5413 \\
\hline & Radius (r) (m) & 92.8313 \\
\hline & Pitch angle $(\beta)$ (in degrees) & 87.6334 \\
\hline & Tip speed ration $(\lambda)$ & 28.438 \\
\hline \multirow{5}{*}{$\begin{array}{l}\text { Results of } \\
\text { airfoils } \\
\text { optimization } \\
\text { for Semnan } \\
\text { data }\end{array}$} & Feature & The value determined \\
\hline & Airfoil type & NACA4314 \\
\hline & Radius (r) (m) & 89.4564 \\
\hline & Pitch angle $(\beta)$ (in degrees) & 89.3597 \\
\hline & Tip speed ration $(\lambda)$ & 28.4772 \\
\hline
\end{tabular}

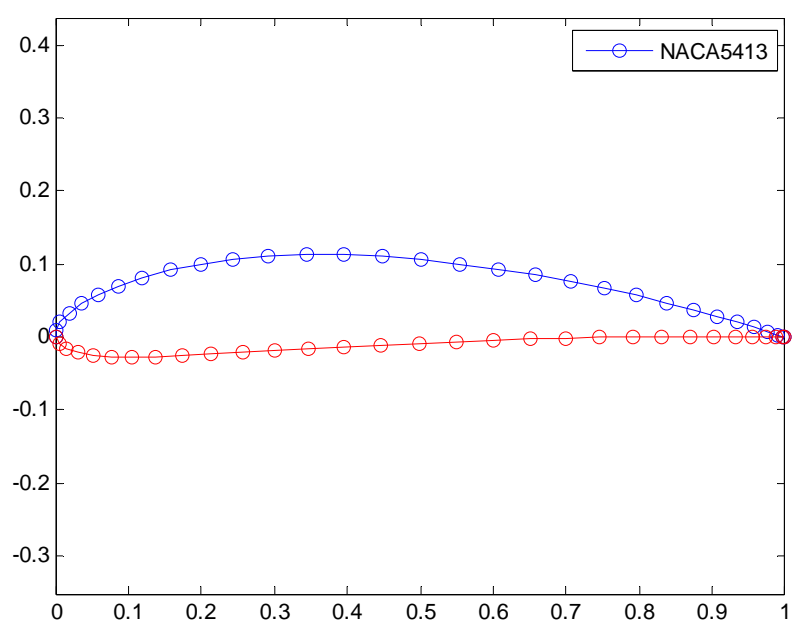

(a)

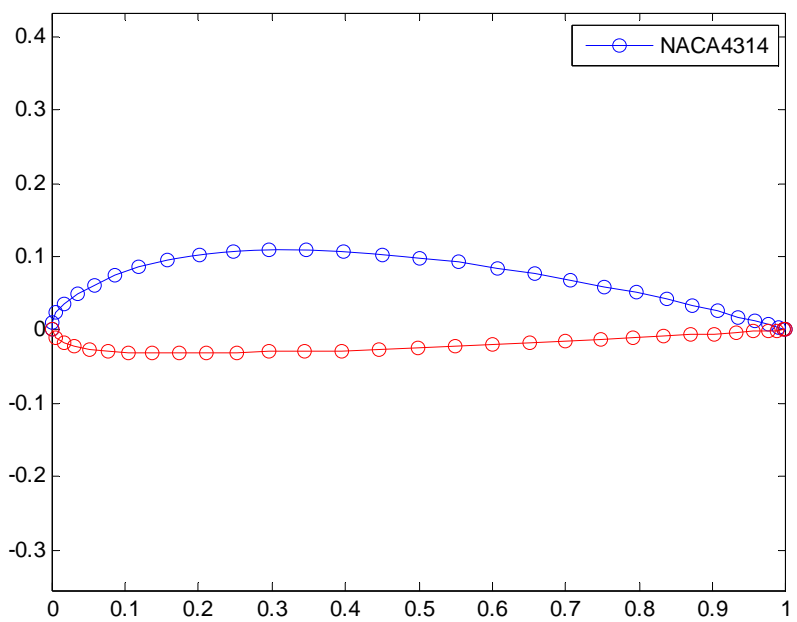

(b)

Figure 12. The airfoils optimization of Manjil and Semnan. (a) The airfoil NACA5413 obtained for Manjil region's optimization data; (b) The airfoil NACA4314 obtained for Semnan region's optimization data. 
3) If the optimum value of a parameter is located outside its designated range (see Section 5), the optimization algorithm cannot find it.

4) A part of the initial population and the genes resulted by mutation are the product a random number and the range of parameters. If the precision of random numbers are not high enough, i.e. there are not enough digits after the separator; the optimum value of the parameters may not be generated through the algorithm. This can be avoided by employing double-precision numbers.

\section{CONCLUSION}

This study proposed a method based on the genetic algorithm for wind turbines' optimization in an attempt to reduce turbine construction cost but to enhance output power. The optimization variables were decided to be blade type and geometric parameters of wind turbines. The method proposed here first calculated the effective wind velocity of the under-study regions employing fuzzy set theory. Using the cost model, the turbine construction cost was obtained in terms of its surface area. The objective function which was considered as a linear combination of cost and power was then fed to the genetic algorithm. The genetic algorithm provided optimal solution(s) by bringing about evolutions in a population of preliminary solutions through successive repetitions. The proposed method was implemented on the wind velocity data obtained from Manjil and Semnan regions in Iran and the wind turbine blades marked by NACA codes. Eventually, the optimal solutions were obtained for every specific region.

\section{REFERENCES}

[1] Kaldellis, J.K. and Zafirakis, D. (2011) The wind energy revolution: A short review of a long history. Renewable Energy, 36, 1887-1901. http://dx.doi.org/10.1016/j.renene.2011.01.002

[2] Mosetti, C.P. and Diviacco, B. (1994) Optimization of wind turbine positioning in large wind farms by means of a genetic algorithm. Journal of Wind Engineering and Industrial Aerodynamics, 51, 105-116. http://dx.doi.org/10.1016/0167-6105(94)90080-9

[3] Fuglsang, P. and Madsen, H.A. (1999) Optimization method for wind turbine rotors. Journal of Wind Engineering and Industrial Aerodynamics, 80, 191-206. http://dx.doi.org/10.1016/S0167-6105(98)00191-3

[4] Benini, E. and Toffolo, A. (2002) Optimal design of horizontal-axis wind turbines using blade element theory and evolutionary computation. Journal of Solar Energy Engineering, 124, 357-363. http://dx.doi.org/10.1115/1.1510868

[5] Jureczko, M., Pawlak, M. and Mezyk, A. (2005) Optimi- sation of wind turbine blades. Journal of Materials Processing Technology, 167, 463-471.

http://dx.doi.org/10.1016/j.jmatprotec.2005.06.055

[6] Minervino, M., Ianelli, P. and Quagliarella, D. (2011) 3d flap design using Navier-Stokes equations and evolutionary optimization techniques on an industrial platform. Cira, Capua.

[7] Kusiak, A., Zheng, H. and Song, Z. (2010) Power optimization of wind turbines with data mining and evolutionary computation. Renewable Energy, 35, 695-702. http://dx.doi.org/10.1016/j.renene.2009.08.018

[8] Kusiak, A. and Zheng, H. (2010) Optimization of wind turbine energy and power factor with an evolutionary computation algorithm. Energy, 35, 1324-1332. http://dx.doi.org/10.1016/j.energy.2009.11.015

[9] Maki, K., Sbragio, R. and Vlahopoulos, N. (2012) System design of a wind turbine using amulti-level optimization approach. Renewable Energy, 43, 101-110. http://dx.doi.org/10.1016/j.renene.2011.11.027

[10] Ameri, M., Ghadiri, M. and Hosseini, M. (2006) Recent advances in the implementation of wind energy in Iran. The 2nd Joint International Conference on Sustainable Energy and Environment, Bangkok.

[11] Keyhani, A., Ghasemi-Varnamkhasti, M., Khanali, M. and Abbaszadeh, R. (2010) An assessment of wind energy potential as a power generation source in the capital of Iran. Tehran. Energy. 35. 188-201. http://dx.doi.org/10.1016/j.energy.2009.09.009

[12] Mostafaeipour, A. (2010) Feasibility study of harnessing wind energy for turbine installation in province of Yazd in Iran. Renewable and Sustainable Energy, 14, 93-111. http://dx.doi.org/10.1016/j.rser.2009.05.009

[13] Mostafaeipour, A., Sedaghat, A., Dehghan-Niri, A.A. and Kalantar, V. (2011) Wind energy feasibility study for city of Shahrbabak in Iran. Renewable and Sustainable Energy, 15, 2545-2556. http://dx.doi.org/10.1016/j.rser.2011.02.030

[14] Jain, P. (2011) Wind energy engineering. McGraw-Hill, New York.

[15] http://raphael.mit.edu/xfoil

[16] Zadeh, L. (1965) Fuzzy sets. Infection Control, 8, 338353. http://dx.doi.org/10.1016/S0019-9958(65)90241-X

[17] Ross, T.J. (2009) Fuzzy logic with engineering applications. Wiley, Hoboken.

[18] Detyniecki, M. and Yager, R.R. (2000) Ranking fuzzy numbers using a weighted valuation. International Journal of Uncertainty, Fuzziness Knowledge-Based Systems, 8, 573-591. http://dx.doi.org/10.1142/S021848850000040X

[19] Goldberg, D.E. (1989) Genetic algorithms in search optimization and machine learning. Adison-Wesley, Boston.

[20] Aryan, P., Mohammadzaheri, M., Chen, L., Ghanbari, M. and Mirsepahi, A. (2010) GA-IMC based PID control design for an infrared dryer. 38th Chemeca Engineering at the Edge, Adelaide, 26-29 September 2010, 3509-3516.

[21] http://www.iranhydrology.com/ 